
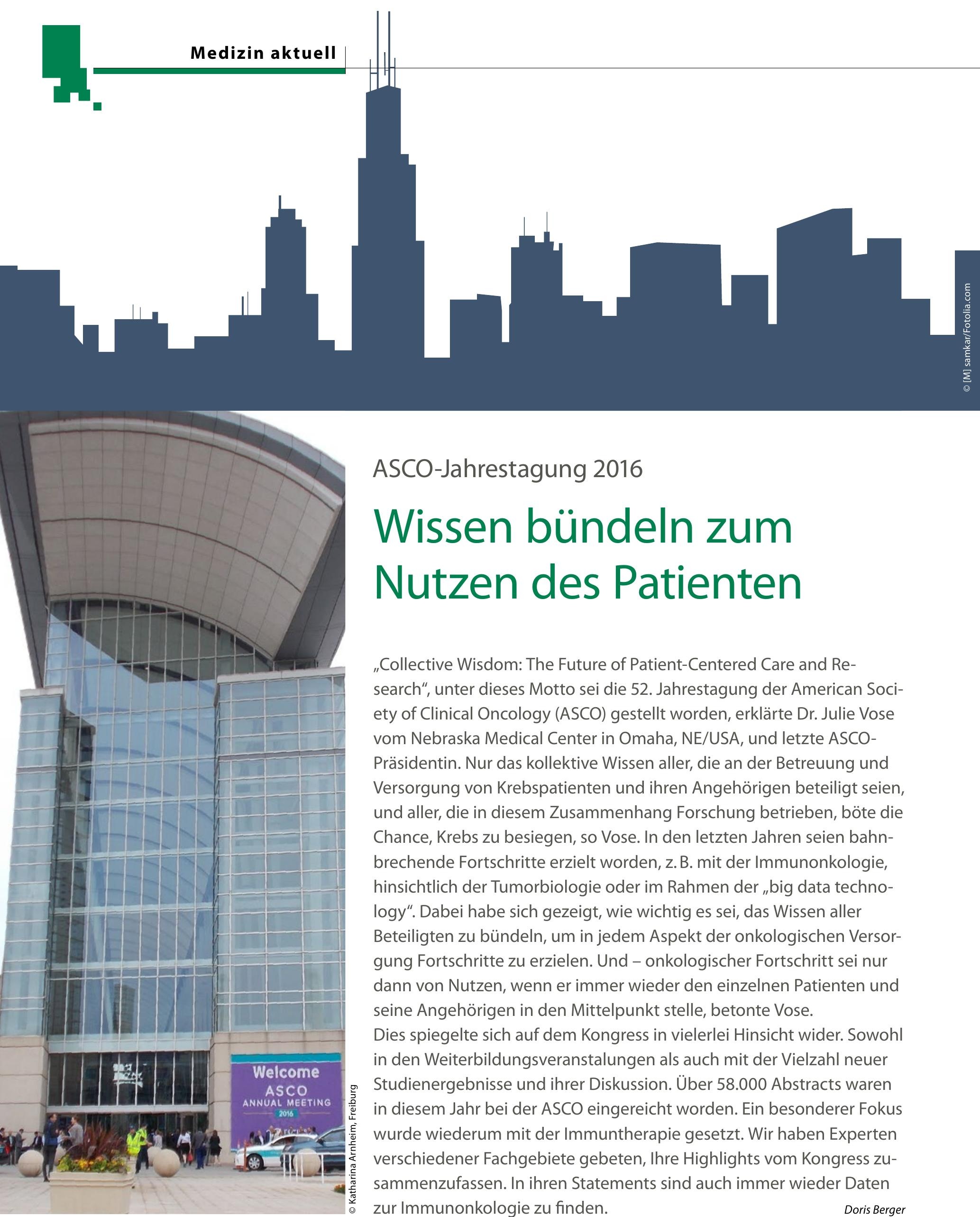

ASCO-Jahrestagung 2016

\title{
Wissen bündeln zum Nutzen des Patienten
}

„Collective Wisdom: The Future of Patient-Centered Care and Research", unter dieses Motto sei die 52. Jahrestagung der American Society of Clinical Oncology (ASCO) gestellt worden, erklärte Dr. Julie Vose vom Nebraska Medical Center in Omaha, NE/USA, und letzte ASCOPräsidentin. Nur das kollektive Wissen aller, die an der Betreuung und Versorgung von Krebspatienten und ihren Angehörigen beteiligt seien, und aller, die in diesem Zusammenhang Forschung betrieben, böte die Chance, Krebs zu besiegen, so Vose. In den letzten Jahren seien bahnbrechende Fortschritte erzielt worden, z. B. mit der Immunonkologie, hinsichtlich der Tumorbiologie oder im Rahmen der „big data technology“. Dabei habe sich gezeigt, wie wichtig es sei, das Wissen aller Beteiligten zu bündeln, um in jedem Aspekt der onkologischen Versorgung Fortschritte zu erzielen. Und - onkologischer Fortschritt sei nur dann von Nutzen, wenn er immer wieder den einzelnen Patienten und seine Angehörigen in den Mittelpunkt stelle, betonte Vose.

Dies spiegelte sich auf dem Kongress in vielerlei Hinsicht wider. Sowohl in den Weiterbildungsveranstalungen als auch mit der Vielzahl neuer Studienergebnisse und ihrer Diskussion. Über 58.000 Abstracts waren in diesem Jahr bei der ASCO eingereicht worden. Ein besonderer Fokus wurde wiederum mit der Immuntherapie gesetzt. Wir haben Experten verschiedener Fachgebiete gebeten, Ihre Highlights vom Kongress zusammenzufassen. In ihren Statements sind auch immer wieder Daten zur Immunonkologie zu finden. 